\title{
Better pulmonary function is associated with greater handgrip strength in a healthy Chinese Han population
}

Liangmei Chen ${ }^{1,2}$, Xiaomin Liu², Qian Wang ${ }^{2}$, Linpei Jia², Kangkang Song ${ }^{2}$, Sasa Nie², Yinping Zhang ${ }^{2}$, Dan Cao ${ }^{2}$, Delong Zhao ${ }^{2}$, Zuoxiang Li ${ }^{2}$, Zheyi Dong ${ }^{2}$, Ying Zheng ${ }^{2}$, Shuwei Duan², Xuefeng Sun ${ }^{2}$, Zhe Feng ${ }^{2}$, Guangyan Cai ${ }^{2}$, Weiguang Zhang ${ }^{2^{*}}$ and Xiangmei Chen ${ }^{1,2^{*}}$ (i)

\begin{abstract}
Background: Handgrip strength (HGS) has been widely studied in clinical and epidemiological settings, but the relationship between HGS and pulmonary function is still controversial. This study analysed pulmonary function and HGS stratified by sex and age in a healthy Chinese Han population, as well as the associations between HGS and pulmonary function parameters.

Methods: HGS was measured by a Jamar dynamometer and pulmonary function was tested using a portable spirometer. Frequencies and variables are presented as percentages and means \pm standard deviations, respectively. Chi-square tests were used for comparisons of categorical variables, and Student's t-tests or Mann-Whitney U-tests were used for continuous variables. Pearson's correlation coefficients were used to analyse the normally distributed variables, and Spearman correlation coefficients were used to analyse the non-normally distributed variables.

Multivariate linear regression models were employed to explore the relationships between HGS and parameters of pulmonary function. The statistical significance was set at $p<0.01$.

Results: Cross-sectional data were available for 1519 subjects ( $59.0 \%$ females, $57.9 \pm 13.3$ years old). Males had higher average HGS than females (40.2 vs. $25.0 \mathrm{~kg}, p<0.01$ ), as well as better pulmonary function. Both HGS and pulmonary function parameters were significantly inversely correlated with age $(r \leq-0.30, p<0.01)$. The maximum value of vital capacity (VC max), forced expiratory volume in $3 \mathrm{~s}$ (FEV 3 ) and forced vital capacity (FVC) were strongly correlated with HGS among the pulmonary function indices $(r=0.72,0.70$ and 0.69 , respectively, $p<0.001)$. In the multivariate linear regression analysis, $\mathrm{HGS}$ and height were positively correlated, while age and pulse pressure were negatively correlated with HGS. In males, the FVC, VC max and FEV3 increased by $0.02 \mathrm{~L}, 0.023 \mathrm{~L}$ and $0.03 \mathrm{~L}$ in per 1 $\mathrm{kg}$ increase in HGS, respectively. The HGS coefficients for females were smaller than those for males.
\end{abstract}

Conclusions: Both pulmonary function and HGS were inversely correlated with age, and better pulmonary function was associated with greater handgrip strength.

Keywords: Handgrip strength, Pulmonary function, Age, Forced vital capacity, Chinese

\footnotetext{
* Correspondence: weiguangzhang1@163.com; xmchen301@126.com

${ }^{2}$ Department of Nephrology, Chinese PLA General Hospital, Chinese PLA

Institute of Nephrology, State Key Laboratory of Kidney Diseases, National

Clinical Research Center of Kidney Diseases, Beijing Key Laboratory of Kidney

Disease, Beijing, China

'Department of Nephrology, The Second Hospital of Jilin University,

Changchun, Jilin, China
}

(c) The Author(s). 2020 Open Access This article is licensed under a Creative Commons Attribution 4.0 International License, which permits use, sharing, adaptation, distribution and reproduction in any medium or format, as long as you give appropriate credit to the original author(s) and the source, provide a link to the Creative Commons licence, and indicate if changes were made. The images or other third party material in this article are included in the article's Creative Commons licence, unless indicated otherwise in a credit line to the material. If material is not included in the article's Creative Commons licence and your intended use is not permitted by statutory regulation or exceeds the permitted use, you will need to obtain permission directly from the copyright holder. To view a copy of this licence, visit http://creativecommons.org/licenses/by/4.0/ The Creative Commons Public Domain Dedication waiver (http://creativecommons.org/publicdomain/zero/1.0/) applies to the data made available in this article, unless otherwise stated in a credit line to the data. 


\section{Background}

The rapid ageing of the population has become an urgent challenge for China and the world. There were nearly 250 million elderly people (aged $>60$ years) by the end of 2018 in China, and it is predicted that the elderly population will grow to approximately 2 billion worldwide by 2050 [1]. Moreover, ageing-associated disorders or diseases are increasing concomitantly.

Pulmonary and musculoskeletal function decline with age, and this phenomenon is not limited to the elderly population. The decline in muscle strength starts at approximately 30 years old and becomes progressive after the age of 65 years $[2,3]$. The mean handgrip strength (HGS) declines from $45.5 \mathrm{~kg}$ to $23.2 \mathrm{~kg}$ for males and from $27.1 \mathrm{~kg}$ to $12.8 \mathrm{~kg}$ for females between the ages of 25 years and 95 years [4]. Pulmonary function declines even in the absence of pulmonary disease $[5,6]$, and it is regarded as an independent predictor of mortality.

The correlation between pulmonary function and HGS has been studied [7-12], but this relationship is still controversial. For example, some researchers have claimed that HGS is associated with the forced expiratory volume in $1 \mathrm{~s}$ (FEV1) in chronic obstructive pulmonary disease (COPD) subjects [12], while other studies have shown that HGS has no association with lung function but may be associated with the quality of life in COPD patients $[8,11]$. More studies have suggested that HGS is positively correlated with parameters of lung function, such as maximum inspiratory pressure [13], forced vital capacity (FVC), FEV1 [14] and peak expiratory flow rate (PEFR) [7]. A cohort study of healthy adolescents revealed that HGS is associated with pulmonary function, while physical activity is not [15].

Most studies on the correlation between pulmonary function and HGS have focused on small samples of individuals with pulmonary disease, stroke, diabetes or other diseases [7-12]. To the best of our knowledge, the association between HGS and pulmonary function has not been investigated in the healthy Chinese Han population.

Therefore, our goal in this study was to analyse pulmonary function and HGS stratified by sex and age in a healthy Chinese Han population, as well as the relationships between HGS and pulmonary function indices.

\section{Methods}

\section{Subjects and study design}

The study was conducted at the Chinese PLA General Hospital in 2016 and recruited volunteers from Beijing, China. All participants received an explanation of the purpose of this investigation and voluntarily provided their consent to participate in this study. All protocols were approved by the Ethics Committee of Chinese PLA General Hospital.
In this study, 2217 volunteers were initially recruited (Fig. 1). A total of 598 subjects were excluded by the following exclusion criteria: (a) those with respiratory diseases, such as chronic obstructive pulmonary disease, asthma, bronchiectasis, etc.; (b) those with musculoskeletal disease or rheumatologic disease, such as sarcopenia, fracture, rheumatoid arthritis, etc.; (c) those with obesity (BMI $\geq 30 \mathrm{~kg} / \mathrm{m}^{2}$ ) or metabolic syndrome; (d) those with chronic disease, such as diabetic mellitus, hypertension, chronic kidney disease, etc.; (e) those with one of the following diseases in the previous 6-month period: liver cirrhosis, stroke, myocardial infarction and malignant tumour; and (e) those unable to cooperate with the tests and sample collection.

\section{Measurements}

All participants completed a questionnaire (Additional file 1: Questionnaire) before their medical examination. Information about their medical history, education level, smoking status, drinking and regular exercise was collected from questionnaire provided by the participants. Subjects who exercised at moderate to maximum intensity at least once per week were considered regular exercisers. The questionnaire and examinations were conducted at the Chinese PLA General Hospital. The health examination included body measurements (height, weight, waist circumference, hip circumference, etc.), blood pressure measurements, laboratory tests, HGS measurements and spirometry.

Haemoglobin (Hb), plasma glucose, albumin (ALB), alanine aminotransferase (ALT), triglyceride (TC) and high-density lipoprotein (HDL) cholesterol levels were analysed. Blood pressure was measured using standard mercury sphygmomanometers. HGS $(\mathrm{kg})$ was measured using a Jamar dynamometer (Sammons Preston Rolyan, Bolingbrook, IL) 3 times with the participant's dominant hand, and the average of the three HGS measurements was used for analysis.

A pulmonary function test was performed by trained medical technicians using a portable spirometer (MasterScreen Pneumo, Hoechberg, Germany) according to the guidelines of the American Thoracic Society/European Respiratory Society [16]. The parameters of pulmonary function are listed in Table 1.

\section{Statistical analysis}

Data were analysed using SPSS 12.0 (SPSS Inc., Chicago, USA). The baseline characteristics are presented as percentages for categorical variables and as the means \pm standard deviations for continuous variables. The baseline characteristics of the study participants stratified by gender were compared using chi-square tests for categorical variables and Student's t-tests or Mann- 


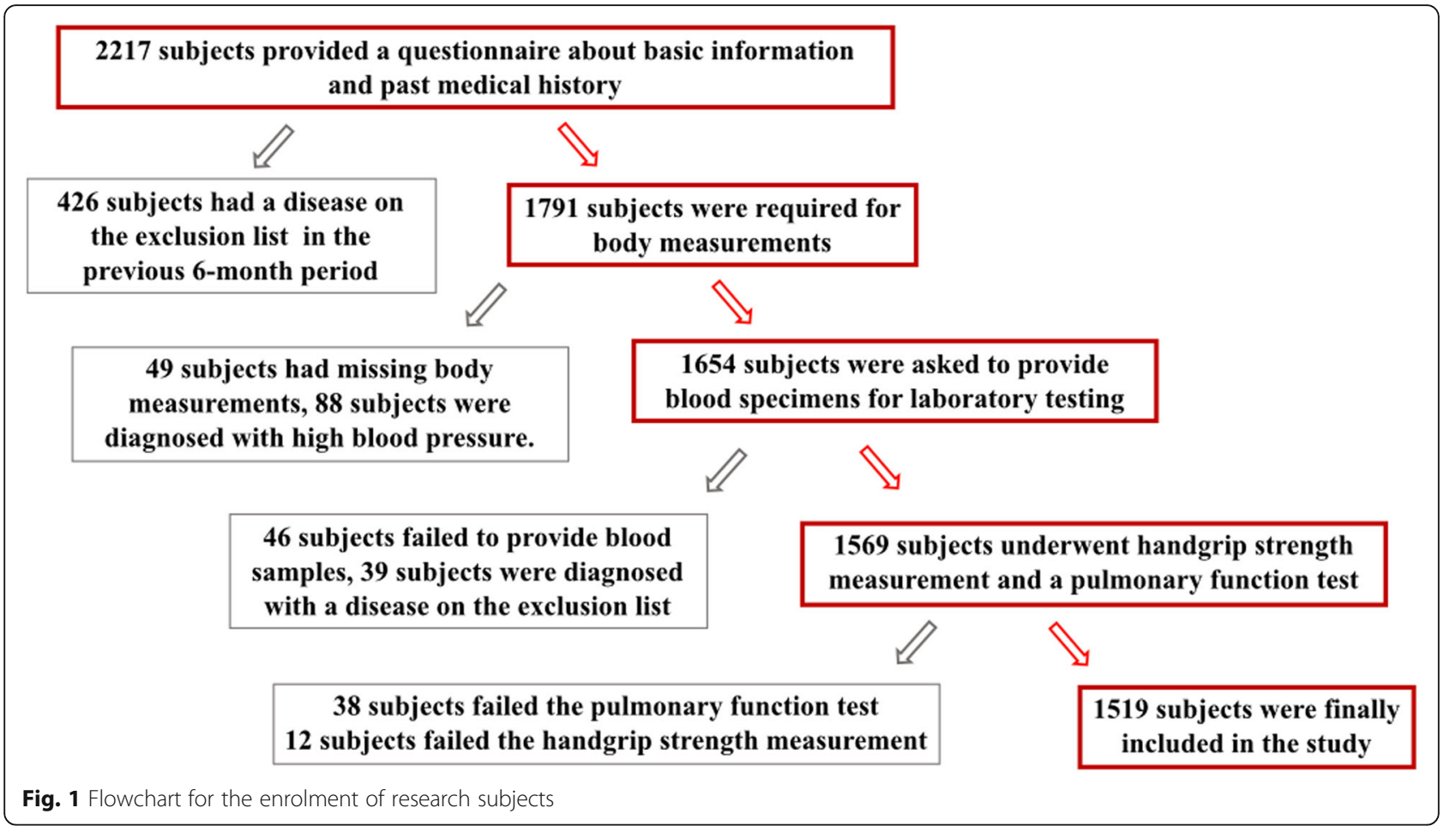

Whitney U-tests for continuous variables. The statistical significance was set at $p<0.01$.

Subjects were divided into the younger group $(<60$ years) and the older group ( $\geq 60$ years). HGS and pulmonary function were compared between these two groups. A correlation analysis was employed to analyse the correlation coefficients of HGS and the pulmonary function parameters with age, the relationship between HGS and pulmonary function parameters, as well as other confounding factors affecting pulmonary function. Pearson's correlation coefficients were used to analyse the normally distributed variables, and Spearman correlation

Table 1 Index of pulmonary function

\begin{tabular}{ll}
\hline Parameters of pulmonary function & Abbreviation \\
\hline inspiratory vital capacity & VC IN \\
expiratory vital capacity & VC EX \\
maximum value of vital capacity & VC max \\
forced vital capacity & FVC \\
forced expiratory volume in 0.5 s & FEV 0.5 \\
forced expiratory volume in 1s & FEV 1 \\
forced expiratory volume in 2s & FEV 2 \\
forced expiratory volume in 3s & FEV 3 \\
maximum expiratory flow rate at 25\% vital capacity & MEF 25 \\
maximum expiratory flow rate at 50\% vital capacity & MEF 50 \\
maximum expiratory flow rate at 75\% vital capacity & MEF 75 \\
maximum ventilation volume & MV \\
\hline
\end{tabular}

coefficients were used to analyse the non-normally distributed variables. Variables with a correlation coefficient

r $\geq 0.30$ and $p<0.01$ were considered to be significantly correlated in our study.

After we identified a linear correlation between HGS and pulmonary function, multivariate linear regression models with VC max, FEV 3 and FVC as dependent variables were conducted to assess the influence of HGS on pulmonary function, with age, height, systolic blood pressure (SBP) and pulse pressure (PP) as independent covariates and "stepwise" as the variable filtering method.

\section{Results}

Baseline characteristics of the study population

Cross-sectional data were available for 1519 subjects $(59.0 \%$ females, $57.9 \pm 13.3$ years old). The demographic and clinical characteristics of the study population are summarized in Table 2. Males had a higher average HGS (40.2 kg) than females $(25.0 \mathrm{~kg})(p<0.01)$; compared with females, males also had better pulmonary function $(p<0.01)$.

\section{Handgrip strength and pulmonary function were negatively associated with age}

The average HGS was significantly higher in the younger group $(33.3 \mathrm{~kg})$ than in the older group $(27.6 \mathrm{~kg})(p<0.01)$. Pulmonary function was also significantly better in the younger group $(p<0.01)$ (Table 3$)$. In the linear correlation analysis, we found that HGS was significantly correlated with age $(\mathrm{r}=-0.30, p<0.01)$, and the parameters of pulmonary 
Table 2 General characteristics of the study population

\begin{tabular}{|c|c|c|c|}
\hline & Males $(n=623)$ & Females $(n=896)$ & Total \\
\hline Age, years & $57.9 \pm 13.5$ & $58.0 \pm 13.2$ & $57.9 \pm 13.3$ \\
\hline Handgrip strength, kg & $40.2 \pm 8.2$ & $25.0 \pm 5.7^{*}$ & $31.5 \pm 10.2$ \\
\hline Height, cm & $170.9 \pm 9.1$ & $159.5 \pm 5.1$ & $164.4 \pm 9.1$ \\
\hline Weight, kg & $73.0 \pm 12.6$ & $61.4 \pm 10.4^{*}$ & $66.4 \pm 12.9$ \\
\hline $\mathrm{BMl}, \mathrm{kg} / \mathrm{m}^{2}$ & $24.8 \pm 4.0$ & $24.1 \pm 4.2$ & $24.4 \pm 4.2$ \\
\hline Waist circumference, cm & $91.4 \pm 9.1$ & $82.9 \pm 11.7$ & $86.6 \pm 11.4$ \\
\hline Hip circumference, $\mathrm{cm}$ & $99.8 \pm 7.5$ & $97.9 \pm 7.3$ & $98.7 \pm 7.4$ \\
\hline Pulse pressure, $\mathrm{mmHg}$ & $50.9 \pm 10.1$ & $53.0 \pm 11.2^{*}$ & $52.1 \pm 10.8$ \\
\hline $\mathrm{Hb}, \mathrm{g} / \mathrm{L}$ & $151.9 \pm 12.3$ & $133.9 \pm 11.4$ & $141.5 \pm 14.7$ \\
\hline Plasma glucose, mmol/L & $5.6 \pm 1.7$ & $5.4 \pm 1.4$ & $5.5 \pm 1.5$ \\
\hline Albumin, $g / L$ & $45.9 \pm 5.0$ & $45.8 \pm 4.5$ & $45.8 \pm 4.8$ \\
\hline Alanine aminotransferase, $\mathrm{U} / \mathrm{L}$ & $24.4 \pm 17.6$ & $19.0 \pm 15.9$ & $21.3 \pm 16.8$ \\
\hline Creatinine, $\mu \mathrm{mol} / \mathrm{L}$ & $83.2 \pm 15.0$ & $65.5 \pm 11.5^{*}$ & $73.1 \pm 15.8$ \\
\hline $\mathrm{TC}, \mathrm{mg} / \mathrm{mL}$ & $4.6 \pm 0.9$ & $4.8 \pm 1.0$ & $4.7 \pm 1.0$ \\
\hline $\mathrm{HDL}, \mathrm{mg} / \mathrm{mL}$ & $1.3 \pm 0.3$ & $1.5 \pm 0.4$ & $1.4 \pm 0.4$ \\
\hline \multicolumn{4}{|l|}{ Education, n (\%) } \\
\hline$\leq$ High school & 60.4 & 62.9 & 61.9 \\
\hline$\geq$ College & 39.6 & 37.1 & 38.1 \\
\hline Regular exercise, $n(\%)$ & 44.3 & 47.5 & 46.2 \\
\hline Drinking, $n(\%)$ & 51.2 & $25.7^{*}$ & 36.1 \\
\hline Cigarette smoking, $n(\%)$ & 32.6 & $5.7^{*}$ & 16.7 \\
\hline \multicolumn{4}{|l|}{ Pulmonary function index } \\
\hline FEV $1(\mathrm{~L})$ & $2.9 \pm 0.7$ & $2.2 \pm 0.5^{*}$ & $2.5 \pm 0.7$ \\
\hline FEV $2(\mathrm{~L})$ & $3.3 \pm 0.7$ & $2.4 \pm 0.5^{*}$ & $2.8 \pm 0.8$ \\
\hline FVC (L) & $3.3 \pm 0.7$ & $2.5 \pm 0.5^{*}$ & $2.8 \pm 0.8$ \\
\hline FEV $0.5(L)$ & $2.3 \pm 0.6$ & $1.7 \pm 0.4^{*}$ & $2.0 \pm 0.5$ \\
\hline MEF $25(L / s)$ & $1.3 \pm 0.6$ & $1.1 \pm 0.5^{*}$ & $1.2 \pm 0.6$ \\
\hline FEV 3 (L) & $3.4 \pm 0.8$ & $2.5 \pm 0.5^{*}$ & $2.8 \pm 0.8$ \\
\hline $\mathrm{VC} \max (\mathrm{L})$ & $3.6 \pm 0.7$ & $2.6 \pm 0.5^{*}$ & $3.1 \pm 0.8$ \\
\hline VC IN (L) & $3.5 \pm 0.8$ & $2.6 \pm 0.6^{*}$ & $3.0 \pm 0.8$ \\
\hline MEF $50(L / s)$ & $3.7 \pm 1.4$ & $3.0 \pm 1.0^{*}$ & $3.3 \pm 1.2$ \\
\hline VC EX (L) & $3.4 \pm 0.8$ & $2.5 \pm 0.6^{*}$ & $2.9 \pm 0.8$ \\
\hline MEF $75(L / S)$ & $6.0 \pm 1.8$ & $4.7 \pm 1.2^{*}$ & $5.2 \pm 1.6$ \\
\hline $\mathrm{MW}(\mathrm{L} / \mathrm{min})$ & $80.3 \pm 27.8$ & $65.7 \pm 20.3^{*}$ & $71.9 \pm 24.9$ \\
\hline
\end{tabular}

${ }^{*} p<0.01$ for comparison with males. BMI body mass index; Hb haemoglobin; TC total cholesterol; HDL high-density lipoprotein; FEV 0.5/1/2/3 forced expiratory volume in $0.5 / 1 / 2 / 3 \mathrm{~s}$; FVC forced vital capacity; VC IN inspiratory vital capacity; VC EX expiratory vital capacity; VC max maximum value of vital capacity; MEF $25 / 50$ / 75 maximum expiratory flow rate at $25 \% / 50 \% / 75 \%$ vital capacity; MVV maximum ventilation volume

function were strongly negatively correlated with age, especially FEV $1(\mathrm{r}=-0.55, p<0.01)$, FEV $2(\mathrm{r}=-0.53, p<0.01)$, FVC $(\mathrm{r}=-0.50, p<0.01)$, FEV $0.5(\mathrm{r}=-0.53, p<0.01)$, and MEF $25(\mathrm{r}=-0.60, p<0.01)$ (Table 3).

\section{Relationship between pulmonary function and handgrip strength}

Pearson correlation analysis showed that VC max had the strongest significant correlation $(\mathrm{r}=0.72, p<0.001)$ with HGS for all participants, followed by VC IN, FEV 3 and FVC ( $\mathrm{r}=0.71 ; 0.70$ and 0.69 , respectively) (Table 4). As both VC max and VC IN are parameters of the vital capacity, we selected VC max, FEV 3 and FVC as representatives of lung function to analyse their associations with HGS.

To identify mixed factors in the relationship between pulmonary function and HGS, we conducted a Pearson correlation analysis between other parameters and 
Table 3 Comparison of handgrip strength and pulmonary function in different age groups and their coefficients of correlation with age

\begin{tabular}{llll}
\hline & $\begin{array}{l}\text { Younger group } \\
(<60 \text { years, } n=725)\end{array}$ & $\begin{array}{l}\text { Older group } \\
(\geq 60 \text { years, } n=794)\end{array}$ & $r$ \\
\hline Handgrip strength & $33.3 \pm 16.4$ & $27.6 \pm 9.4^{*}$ & -0.30 \\
FEV 1 (L) & $2.8 \pm 0.6$ & $2.2 \pm 0.6^{*}$ & -0.55 \\
FEV 2 (L) & $3.1 \pm 0.8$ & $2.5 \pm 0.7^{*}$ & -0.53 \\
FVC (L) & $3.1 \pm 0.8$ & $2.6 \pm 0.7^{*}$ & -0.50 \\
FEV 0.5 (L) & $2.2 \pm 0.5$ & $1.7 \pm 0.4^{*}$ & -0.53 \\
MEF 25 (L/s) & $1.3 \pm 0.6$ & $1.1 \pm 0.5^{*}$ & -0.60 \\
FEV 3 (L) & $3.2 \pm 0.8$ & $2.6 \pm 0.7^{*}$ & -0.47 \\
VC max (L) & $3.4 \pm 0.8$ & $2.7 \pm 0.7^{*}$ & -0.46 \\
VC IN (L) & $3.2 \pm 0.8$ & $2.7 \pm 0.8^{*}$ & -0.44 \\
MEF 50 (L/s) & $3.8 \pm 1.1$ & $2.8 \pm 1.1^{*}$ & -0.50 \\
VC EX (L) & $3.1 \pm 0.8$ & $2.6 \pm 0.7^{*}$ & -0.41 \\
MEF 75 (L/s) & $5.7 \pm 1.5$ & $4.8 \pm 1.5^{*}$ & -0.39 \\
MW (L/min) & $79.6 \pm 24.1$ & $64.6 \pm 23.4^{*}$ & -0.38 \\
\hline * 0 0.01 for compaison & &
\end{tabular}

${ }^{*} p<0.01$ for comparison with the younger group;

$r$ is the correlation coefficient between the parameters and age; all correlation coefficients listed are significant at the 0.01 level. Spearman correlation coefficient was used to analyse MVV (with non-normal distribution), and Pearson's correlation coefficients were used to analyse the normally distributed variables

Table 4 Correlation coefficients between handgrip strength and parameters of pulmonary function stratified by sex

\begin{tabular}{llll}
\hline Parameters of Pulmonary Function & $\begin{array}{l}\text { Males } \\
(n=623)\end{array}$ & $\begin{array}{l}\text { Females } \\
(n=896)\end{array}$ & $\begin{array}{l}\text { Total } \\
(n=1519)\end{array}$ \\
\hline VC max & $0.48^{*}$ & $0.51^{*}$ & $0.72^{*}$ \\
VC IN & $0.47^{*}$ & $0.50^{*}$ & $0.71^{*}$ \\
FEV 3 & $0.48^{*}$ & $0.50^{*}$ & $0.70^{*}$ \\
FVC & $0.49^{*}$ & $0.50^{*}$ & $0.69^{*}$ \\
FEV 2 & $0.48^{*}$ & $0.52^{*}$ & $0.69^{*}$ \\
FEV 1 & $0.48^{*}$ & $0.46^{*}$ & $0.65^{*}$ \\
VC EX & $0.42^{*}$ & $0.43^{*}$ & $0.65^{*}$ \\
FEV 0.5 & $0.45^{*}$ & $0.43^{*}$ & $0.62^{*}$ \\
MEF 75 & $0.34^{*}$ & $0.35^{*}$ & $0.52^{*}$ \\
MW & $0.33^{*}$ & $0.35^{*}$ & $0.41^{*}$ \\
MEF 50 & $0.34^{*}$ & $0.30^{*}$ & $0.40^{*}$ \\
MEF 25 & $0.30^{*}$ & $0.31^{*}$ & $0.30^{*}$ \\
\hline
\end{tabular}

FEV 0.5/1/2/3: forced expiratory volume in 0.5/1/2/3 s; FVC forced vital capacity; VC IN inspiratory vital capacity; VC EX expiratory vital capacity; VC max maximum value of vital capacity; MEF 25/50/75 maximum expiratory flow rate at $25 \% / 50 \% / 75 \%$ vital capacity; $M V V$ maximum ventilation volume. ${ }^{*} p<$ 0.001 for the correlation coefficients listed. Spearman correlation coefficients were used to analyse MVV (with non-normal distribution) and MEF 25 (with non-normal distribution only when analysis was stratified by gender). Pearson's correlation coefficients were used to analyse the normally distributed variables pulmonary function (VC max, FEV3 and FVC) (Table 5). HGS, age, height, SBP and PP were significantly correlated with pulmonary function ( $\mathrm{r} \quad \geq 0.30, p<0.01$ ).

Then we conducted a series of multivariate linear regression analyses to explore the relationships between pulmonary function (VC max, FVC and FEV3) and four independent variables (HGS, age, height, SBP and PP) (Table 6). The results showed that height and HGS had positive coefficients in multivariate linear regression models, and age and PP had negative coefficients, while SBP was excluded. In males, the FVC, VC max and FEV3 increased by $0.02 \mathrm{~L}, 0.023 \mathrm{~L}$ and $0.03 \mathrm{~L}$ in per $1 \mathrm{~kg}$ increase in HGS, respectively. The average annual decrease in the FVC, VC max and FEV3 in males was $0.024 \mathrm{~L}, 0.022 \mathrm{~L}$ and $0.028 \mathrm{~L}$, respectively. Compared with males, the effect of age and HGS on pulmonary function was smaller in females, while the effect of height was greater.

\section{Discussion}

Ageing is often accompanied by the functional degradation of multiple organs and systems and the development of ageing-related diseases. The muscular system is characterized by a decrease in muscle mass and a decline in muscle strength during the aging process, and this degradation actually starts at approximately 30 years old [2]. In this cross-sectional study, HGS was negatively associated with age, and the older group had a significantly lower HGS than the younger group. A longitudinal study showed that in people aged 75 years or older, the loss of muscle mass was $0.64-0.70 \%$ and $0.80-0.98 \%$ per year in females and males, respectively [17]. The loss of muscle strength is $2.5-3 \%$ and $3-4 \%$ per year in females and males, respectively [18].

Research shows that in Caucasian men after the age of 35 years, lung function begins to decline with increasing age [19], and our study also showed that pulmonary function is negatively correlated with age in a healthy Han Chinese population. Some researchers have reported that ageing might weaken pulmonary function by decreasing the respiratory muscle mass and muscle strength $[6,20]$.

It is worth mentioning that muscle strength has attracted interest in recent years because a strong and inverse association of muscle strength with all-cause mortality has been confirmed in several populations, such as subjects with cardiovascular disease [21], cancer [22], respiratory disease [23], and chronic obstructive pulmonary disease [24]. HGS, which is a simple, noninvasive and objective marker of muscle strength $[25,26]$, is widely used in studies of muscle strength.

Moreover, the Prospective Urban Rural Epidemiology (PURE) Study has reported the prognostic value of HGS for all-cause mortality, cardiovascular mortality and 
Table 5 Correlation coefficients ( $r$ ) of variables with pulmonary function in males and females

\begin{tabular}{|c|c|c|c|c|c|c|}
\hline \multirow[t]{2}{*}{ Variables } & \multicolumn{2}{|l|}{ VC max } & \multicolumn{2}{|l|}{ FEV3 } & \multicolumn{2}{|l|}{ FVC } \\
\hline & Males & Females & Males & Females & Males & Females \\
\hline Handgrip strength & 0.507 & 0.481 & 0.504 & 0.476 & 0.497 & 0.486 \\
\hline Age & -0.573 & -0.604 & -0.59 & -0.605 & -0.611 & -0.614 \\
\hline Height & 0.304 & 0.518 & 0.192 & 0.508 & 0.281 & 0.504 \\
\hline Weight & 0.226 & 0.125 & 0.186 & 0.161 & 0.216 & 0.128 \\
\hline BMl & 0.053 & -0.065 & 0.083 & -0.053 & 0.062 & -0.055 \\
\hline Waist circumference & -0.017 & -0.156 & 0.02 & -0.185 & -0.013 & -0.155 \\
\hline Hip circumference & 0.116 & 0.027 & 0.15 & 0.006 & 0.115 & 0.028 \\
\hline SBP & -0.182 & -0.332 & -0.118 & -0.278 & -0.186 & -0.334 \\
\hline DBP & -0.044 & -0.146 & 0.063 & -0.117 & -0.04 & -0.136 \\
\hline PP & -0.294 & -0.38 & -0.231 & 0.325 & -0.303 & -0.385 \\
\hline $\mathrm{Hb}$ & 0.240 & 0.017 & 0.303 & 0.030 & 0.263 & 0.016 \\
\hline Plasma glucose & -0.172 & -0.265 & -0.146 & -0.356 & -0.186 & -0.261 \\
\hline Albumin, g/L & 0.125 & 0.087 & 0.144 & 0.089 & 0.148 & 0.114 \\
\hline Alanine aminotransferase & 0.162 & -0.101 & 0.197 & -0.102 & 0.183 & -0.079 \\
\hline Creatinine & -0.066 & -0.104 & 0.009 & 0.019 & -0.085 & -0.114 \\
\hline TC & -0.014 & -0.067 & 0.059 & 0.003 & 0.004 & -0.043 \\
\hline $\mathrm{HDL}$ & -0.15 & -0.005 & -0.202 & -0.016 & -0.154 & -0.015 \\
\hline
\end{tabular}

The data shown in bold are variables with values of $|r|>0.30$ and $p<0.01$. Spearman correlation coefficients were used to analyse levels of plasma glucose and alanine aminotransferase (with non-normal distribution in both males and females). Pearson's correlation coefficients were used to analyse the normally distributed variables.VC max: maximum value of vital capacity; FVC forced vital capacity; FEV3 forced expiratory volume in $3 \mathrm{~s}$; BMI body mass index; SBP systolic blood pressure; DBP diastolic blood pressure; PP pulse pressure; $H b$ haemoglobin; TC triglycerides; $H D L$ high-density lipoprotein.

cardiovascular disease independent of confounding factors, such as dietary habits, physical activity levels and socioeconomic status [21, 27]. Overall, its simplicity of measurement, portability, low cost and prognostic value make HGS an attractive and important means of evaluating an individual's overall health in clinical or epidemiological settings $[27,28]$.
Given the importance of HGS, the Prospective Urban Rural Epidemiology (PURE) Study reported reference ranges of HGS from 125,462 healthy adults in 21 countries, including China. The median HGS in the Chinese population aged 51-60 years reported in the PURE study was $26 \mathrm{~kg}$ in women and $40 \mathrm{~kg}$ in men [27], which is consistent with our results (women $25.0 \mathrm{~kg}$, men $40.2 \mathrm{~kg}$ ).

Table 6 The coefficients of variables in multivariate linear regression models assessing the associations between pulmonary parameters and HGS

\begin{tabular}{|c|c|c|c|c|c|c|c|c|c|}
\hline \multirow[t]{2}{*}{ Gender } & \multirow{2}{*}{$\begin{array}{l}\text { Independent } \\
\text { Variables }\end{array}$} & \multicolumn{4}{|c|}{ Unstandardized coefficients } & \multicolumn{4}{|c|}{ Standardized coefficients (95\% Cl) } \\
\hline & & Age & HGS & Height & $\mathrm{PP}$ & Age & HGS & Height & PP \\
\hline \multirow[t]{3}{*}{ Male } & FVC & $\overline{-} .024$ & 0.020 & 0.012 & -0.010 & $-0.449(-0.524,-0.374)$ & $\begin{array}{l}0.225(0.158, \\
0.293)\end{array}$ & $\begin{array}{l}0.148(0.086, \\
0.210)\end{array}$ & $\begin{array}{l}-0.130(-0.182,- \\
0.065)\end{array}$ \\
\hline & VC max & $\overline{-} .022$ & 0.023 & 0.014 & $\overline{-} .010$ & $\begin{array}{l}-0.396(-0.468,- \\
0.324)\end{array}$ & $\begin{array}{l}0.254(0.177 \\
0.320)\end{array}$ & $\begin{array}{l}0.168(0.096, \\
0.228)\end{array}$ & $-0.134(-0.201,-0.067)$ \\
\hline & FEV3 & $-\overline{0.028}$ & 0.030 & / & / & $-0.464(-0.580,-0.348)$ & $\begin{array}{l}0.303(0.182, \\
0.424)\end{array}$ & / & / \\
\hline \multirow[t]{3}{*}{ Female } & FVC & -0.017 & 0.018 & 0.034 & -0.005 & $-0.407(-0.479,-0.359)$ & $\begin{array}{l}0.182(0.121 \\
0.233)\end{array}$ & $\begin{array}{l}0.319(0.272, \\
0.375)\end{array}$ & $-0.097(-0.155,-0.039)$ \\
\hline & VC max & -0.016 & 0.017 & 0.036 & -0.005 & $-0.393(-0.467,-0.344)$ & $\begin{array}{l}0.175(0.124 \\
0.226)\end{array}$ & $\begin{array}{l}0.337(0.290, \\
0.393)\end{array}$ & $-0.101(-0.162,-0.040)$ \\
\hline & FEV3 & -0.021 & 0.019 & 0.035 & / & $-0.447(-0.532,-0.362)$ & $\begin{array}{l}0.194(0.102, \\
0.286)\end{array}$ & $\begin{array}{l}0.324(0.231 \\
0.407)\end{array}$ & / \\
\hline
\end{tabular}


In our study, pulmonary function parameters showed strong, positive correlations with HGS. We further showed that HGS was independently correlated with spirometry. Our results were consistent with previous studies, supporting the conclusion that better respiratory function is associated with greater HGS [13-15, 29-31]. Some studies reported that HGS is a significant predictor of pulmonary function in healthy young adults [32], and some concluded that strength training might improve lung health in adolescents and renal transplant recipients $[15,33]$.

In addition to HGS, we also found other factors affected lung function, including sex, age, height and PP; these findings were also consistent with those of other studies [7, 9]. Meanwhile, measures of adiposity (such as waist circumference, waist-hip ratio, fat mass, percentage body fat, etc.) and HDL cholesterol were shown to be significantly inversely correlated with pulmonary function in other studies [34, 35].

In this study, we reported the general characteristics of HGS and pulmonary function in a healthy Chinese Han population, as well as the relationship between them: HGS is positively associated with pulmonary function. This study also has several limitations. First, this was a cross-sectional study with a limited sample size and only included individuals belonging to the Chinese Han population. Second, we observed these phenomena in a single centre but failed to explore the intrinsic mechanisms underlying the relationship between HGS and pulmonary function. Further research is needed to identify whether and how HGS can influence pulmonary function.

\section{Conclusions}

In conclusion, HGS and pulmonary function indices were significantly inversely correlated with age, and HGS was positively related to pulmonary function.

\section{Supplementary information}

Supplementary information accompanies this paper at https://doi.org/10. 1186/s12890-020-1155-5.

Additional file 1. Questionnaire used in this study.

\footnotetext{
Abbreviations

HGS: Handgrip strength; COPD: Chronic obstructive pulmonary disease; PEFR: Peak expiratory flow rate; Hb: Haemoglobin; ALB: Albumin; ALT: Alanine aminotransferase; TC: Triglyceride; HDL: High-density lipoprotein; SBP: Systolic blood pressure; PP: Pulse pressure; VC IN: Inspiratory vital capacity; VC EX: Expiratory vital capacity; VC max: Maximum value of vital capacity; FVC: Forced vital capacity; FEV 0.5: Forced expiratory volume in 0.5 s; FEV 1: Forced expiratory volume in $1 \mathrm{~s}$; FEV 2: Forced expiratory volume in $2 \mathrm{~s}$; FEV 3: Forced expiratory volume in $3 \mathrm{~s}$; MEF 25: Maximum expiratory flow rate at 25\% vital capacity; MEF 50: Maximum expiratory flow rate at 50\% vital capacity; MEF 75: Maximum expiratory flow rate at 75\% vital capacity; MW: Maximum ventilation volume
}

\section{Acknowledgements}

The authors would like to express their gratitude to all the individuals who participated in this study.

\section{Authors' contributions}

$X C$ and WZ conceived of and designed the study; LC analysed and interpreted the data, drafted and revised the manuscript; XC, QW, KS, SN and DZ surveyed the subjects. ZL, ZD, YZ and SD performed body measurements of the subjects. $Y Z$ and DC collected blood samples from the subjects. $L$ analysed the blood samples. XS, ZF and GC recruited the subjects. All the authors have read and approved the final manuscript.

\section{Funding}

The National Basic Research Program of China (No. 2015CB553605) supported the study in study design. The National Key R\&D Program of China (No. 2016YFC1305500, 2016YFC1305503) and the Natural Science Foundation of China (No. 81601211, No. 8160050078) supported the study in the examinations and data collection. The Science \& Technology Project of Beijing (No. D171100002817002) and the Beijing Municipal Science and Technology Project (No. Z181100001918015) supported the study in data analysis and interpretation. The Science and Technology Development Plan Project of Jilin Province (No. 20180520126JH) supported the study in writing the manuscript.

\section{Availability of data and materials}

The data used to support the findings of this study are available from the corresponding author upon reasonable request.

\section{Ethics approval and consent to participate}

This study was approved by the academic ethics and moral supervision committee of the Chinese PLA General Hospital. All participants signed informed consent before participating in this study, and the purpose of the study was explained to the participants in advance.

\section{Consent for publication}

Written informed consent was obtained from all participants prior to inclusion in this study.

\section{Competing interests}

The authors declare that there are no potential conflicts of interest to disclose.

Received: 10 September 2019 Accepted: 20 April 2020

Published online: 29 April 2020

\section{References}

1. Fuster V. Changing demographics. J Am Coll Cardiol. 2017;69(24):3002-5.

2. Frontera WR, Suh D, Krivickas LS, Hughes VA, Goldstein R, Roubenoff R. Skeletal muscle fiber quality in older men and women. Am J Physiol Cell Physiol. 2000:279(3):C611-8.

3. Sehl ME, Yates FE. Kinetics of human aging: I. rates of senescence between ages 30 and 70 years in healthy people. J Gerontol a-Biol. 2001;56(5):B198208.

4. Beenakker KG, Ling CH, Meskers CG, de Craen AJ, Stijnen T, Westendorp RG, Maier AB. Patterns of muscle strength loss with age in the general population and patients with a chronic inflammatory state. Ageing Res Rev. 2010;9(4):431-6.

5. Kim J, Heise RL, Reynolds AM, Pidaparti RM. Aging effects on airflow dynamics and lung function in human bronchioles. PLoS One. 2017;12(8): e0183654.

6. Skloot GS. The effects of aging on lung structure and function. Clin Geriatr Med. 2017;33(4):447-57.

7. Holmes SJ, Allen SC, Roberts HC. Relationship between lung function and grip strength in older hospitalized patients: a pilot study. Int J Chron Obstruct Pulmon Dis. 2017;12:1207-12.

8. Jeong M, Kang HK, Song P, Park HK, Jung H, Lee SS, Koo HK. Hand grip strength in patients with chronic obstructive pulmonary disease. Int J Chron Obstruct Pulmon Dis. 2017;12:2385-90.

9. Cichosz SL, Vestergaard ET, Hejlesen O. Muscle grip strength is associated to reduced pulmonary capacity in patients with diabetes. Prim Care Diabetes. 2018;12(1):66-70. 
10. Kim N-S. Correlation between grip strength and pulmonary function and respiratory muscle strength in stroke patients over 50 years of age. J Exer Rehab. 2018;14(6):1017-23.

11. Lee SH, Kim SJ, Han Y, Ryu YJ, Lee JH, Chang JH. Hand grip strength and chronic obstructive pulmonary disease in Korea: an analysis in KNHANES VI. Int J Chron Obstruct Pulmon Dis. 2017:12:2313-21.

12. Strandkvist VJ, Backman H, Roding J, Stridsman C, Lindberg A. Hand grip strength is associated with forced expiratory volume in 1 second among subjects with COPD: report from a population-based cohort study. Int J Chron Obstruct Pulmon Dis. 2016;11:2527-34.

13. Efstathiou ID, Mavrou IP, Grigoriadis KE. Correlation between maximum inspiratory pressure and hand-grip force in healthy young and middle-age individuals. Respir Care. 2016;61(7):925-9.

14. Sillanpaa E, Stenroth L, Bijlsma AY, Rantanen T, McPhee JS, Maden-Wilkinson TM, Jones DA, Narici MV, Gapeyeva H, Paasuke M, et al. Associations between muscle strength, spirometric pulmonary function and mobility in healthy older adults. Age (Dordr). 2014;36(4):9667.

15. Smith MP, Standl M, Berdel D, von Berg A, Bauer C-P, Schikowski T, et al. Handgrip strength is associated with improved spirometry in adolescents. PLOS ONE. 2018;13(4):e0194560.

16. Miller MR, Hankinson J, Brusasco V, Burgos F, Casaburi R, Coates A, Crapo R, Enright $P$, van der Grinten CP, Gustafsson P, et al. Standardisation of spirometry. Eur Respir J. 2005;26(2):319-38.

17. Tieland M, Trouwborst I, Clark BC. Skeletal muscle performance and ageing. J Cachexia Sarcopenia Muscle. 2018;9(1):3-19.

18. Mitchell WK, Williams J, Atherton P, Larvin M, Lund J, Narici M. Sarcopenia, dynapenia, and the impact of advancing age on human skeletal muscle size and strength; a quantitative review. Front Physiol. 2012;3:260.

19. Poon AH, Houseman EA, Ryan L, Sparrow D, Vokonas PS, Litonjua AA. Variants of asthma and chronic obstructive pulmonary disease genes and lung function decline in aging. J Gerontol A Biol Sci Med Sci. 2014;69(7): 907-13.

20. Miller MR. Structural and physiological age-associated changes in aging lungs. Semin Respir Crit Care Med. 2010;31(5):521-7.

21. Leong DP, Teo KK, Rangarajan S, Lopez-Jaramillo P, Avezum A Jr, Orlandini A, Seron P, Ahmed SH, Rosengren A, Kelishadi R, et al. Prognostic value of grip strength: findings from the prospective urban rural epidemiology (PURE) study. Lancet. 2015:386(9990):266-73.

22. Ruiz JR, Sui X, Lobelo F, Morrow JR, Jackson AW, Sjostrom M, Blair SN. Association between muscular strength and mortality in men: prospective cohort study. BMJ. 2008;337:a439.

23. Celis-Morales CA, Welsh P, Lyall DM, Steell L, Petermann F, Anderson J, Iliodromiti S, Sillars A, Graham N, Mackay DF, et al. Associations of grip strength with cardiovascular, respiratory, and cancer outcomes and all cause mortality: prospective cohort study of half a million UK biobank participants. BMJ. 2018;361:k1651

24. Volaklis KA, Halle M, Meisinger C. Muscular strength as a strong predictor of mortality: a narrative review. Eur J Intern Med. 2015;26(5):303-10.

25. Ostrowski S, Barud W. Factors influencing lung function: are the predicted values for spirometry reliable enough? J Physiol Pharmacol. 2006;57(Suppl 4):263-71.

26. Rijk JM, Roos PR, Deckx L, van den Akker M, Buntinx F. Prognostic value of handgrip strength in people aged 60 years and older: a systematic review and meta-analysis. Geriatr Gerontol Int. 2016;16(1):5-20.

27. Leong DP, Teo KK, Rangarajan S, Kutty VR, Lanas F, Hui C, Quanyong X, Zhenzhen Q, Jinhua T, Noorhassim I, et al. Reference ranges of handgrip strength from 125,462 healthy adults in 21 countries: a prospective urban rural epidemiologic (PURE) study. J Cachexia Sarcopenia Muscle. 2016;7(5): 535-46.

28. Koivistoinen T, Lyytikainen LP, Aatola H, Luukkaala T, Juonala M, Viikari J, Lehtimaki T, Raitakari OT, Kahonen M, Hutri-Kahonen N. Pulse wave velocity predicts the progression of blood pressure and development of hypertension in young adults. Hypertension. 2018;71(3):451-6.

29. Smith MP, Muller J, Neidenbach R, Ewert P, Hager A. Better lung function with increased handgrip strength, as well as maximum oxygen uptake, in congenital heart disease across the lifespan. Eur J Prev Cardiol. 2019;26(5): 492-501.

30. Bahat G, Tufan A, Ozkaya H, Tufan F, Akpinar TS, Akin S, Bahat Z, Kaya Z,

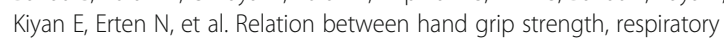
muscle strength and spirometric measures in male nursing home residents. Aging Male. 2014;17(3):136-40.
31. Son D-H, Yoo J-W, Cho M-R, Lee Y-J. Relationship between handgrip strength and pulmonary function in apparently healthy older women. J Am Geriatr Soc. 2018;66(7):1367-71.

32. Mgbemena NC, Aweto HA, Tella BA, Emeto TI, Malau-Aduli BS. Prediction of lung function using handgrip strength in healthy young adults. Physiol Rep. 2019;7(1):e13960.

33. Ulubay G, Uyanik S, Er Dedekarginoglu B, Serifoglu I, Kupeli E, Savas Bozbas S, Sezer S, Haberal M. Peripheral muscle strength indicates respiratory function testing in renal recipients. Exp Clin Transplant. 2017;15(Suppl 1): 249-53.

34. Wannamethee SG, Shaper AG, Whincup PH. Body fat distribution, body composition, and respiratory function in elderly men. Am J Clin Nutr. 2005; 82(5):996-1003.

35. Cirillo DJ, Agrawal Y, Cassano PA. Lipids and pulmonary function in the third National Health and nutrition examination survey. Am J Epidemiol. 2002;155(9):842-8.

\section{Publisher's Note}

Springer Nature remains neutral with regard to jurisdictional claims in published maps and institutional affiliations.
Ready to submit your research? Choose BMC and benefit from:

- fast, convenient online submission

- thorough peer review by experienced researchers in your field

- rapid publication on acceptance

- support for research data, including large and complex data types

- gold Open Access which fosters wider collaboration and increased citations

- maximum visibility for your research: over $100 \mathrm{M}$ website views per year

At $\mathrm{BMC}$, research is always in progress.

Learn more biomedcentral.com/submissions 